\title{
Silent Strokes is a Risk for Epilepsy in Elderly Population
}

\author{
Mohammed Tahir ${ }^{1}$, Mutaz F Hummadi ${ }^{2}$, Jaafer M. Kurmanji ${ }^{3}$, Ihsan K. Al-Shimmery4 ${ }^{4}$ \\ ${ }^{1}$ Lecturer, Medical College, Sulymania University, Sulymania. \\ 2Lecturer, Neurology chapter, Department of Medicine, Hawler Teaching Hospital, Hawler. \\ ${ }^{3}$ Lecturer, Pharmacy Department, Israa University College, Baghdad. \\ ${ }^{4}$ Consultant, Neurology Unit, Department of Medicine, Rezgary Teaching Hospital, Hawler, IRAQ.
}

\begin{abstract}
Purpose: To show the significance of silent strokes among middle age and elderly patients having late onset epilepsy.

Methods: This cross-sectional study (survey) was carried out at Rizgary Teaching Hospital, Erbil, Iraq from January to May, 2010. Patients were included in this study if they were middle aged and elderly patients (age range 50 and above) having unprovoked acquired first seizure or multiple seizures, previously or recently diagnosed as epileptic regardless the number of fits which could be single or multiple, having history of recent or old stroke or TIA and now presented with seizure. 100 Iraqi patients were included in this survey. The MRI images were examined and interpreted through collaborative discussions between a consultant Radiologist and a consultant Neurologist (T1, T2 and FLAIR sequences were obtained) and almost all patients had abnormal EEG studies.

Data were tabulated and analyzed, the significance of certain parameters was measured using chi square test, $p$-value of $\leq 0.05$ was considered statistically significant.

Key findings: In this study males outnumber females, epilepsy was mostly observed in elderly population (70-79 years) and $p$ value was not significant regarding sex differences in the studied sample. Silent strokes were observed mostly in elderly population (63-67\%). Hypertension, hyperlipidemia, smoking, and old strokes are the commonest comorbidities observed in
\end{abstract}

\section{INTRODUCTION}

Stroke is defined as the sudden occurrence of a non-convulsive, focal neurological deficit lasting more than 24 hours. ${ }^{1,2}$ Pathologically speaking, stroke falls into three subtypes, ischemic stroke (about $80 \%$ ), Primary intra-cerebral hemorrhage (about $15 \%$ ), and subarachnoid hemorrhage (about 5\%). Cerebral ischemia usually caused by a reduction in blood flow that lasts for several seconds to a few minutes. ${ }^{3-5}$

Silent cerebral infarction (SCI) is defined as a brain lesion that is presumably a result of vascular occlusion found incidentally by magnetic resonance imaging (MRI) or computed tomography (CT) or when small blood vessels in the brain become blocked or ruptured without signs and symptoms in otherwise healthy subjects or discovered during autopsy. ${ }^{6,7} \mathrm{SCls}$ also termed covert infarcts or simply MRI infarcts. ${ }^{8}$

SCls may occur without apparent clinical manifestations, however, either because the patient and family are unaware of minor symptoms or a so-called silent area of brain has been affected. ${ }^{9}$ The SCls are frequently demonstrated in the subcortical white matter or the basal ganglia in stroke patients and elderly subjects. ${ }^{10}$ relation to epileptic patients with silent strokes, and partial secondary generalized epilepsy type was the commonest epilepsy variety observed $(73 \%)$ followed by partial complex epilepsy $(12 \%)$ and simple partial epilepsy $(11 \%)$.

Significance: Silent strokes were common in elderly patients having epilepsy $(53 \%)$, especially patients having stroke risk factors like hypertension, and its prevalence increase with age. Silent strokes can be an indirect way to establish the causes of epilepsy in elderly population as having silent cortical ischemia.

Key words: Epilepsy, Elderly, Silent strokes.

\section{*Correspondence to:}

Ihsan K. Al-Shimmery, Neurology Unit, Department of Medicine, Rezgary Teaching Hospital, Erbil, Iraq.

Email: ihsanshimmery@gmail.com

Article History:

Received: 10-04-2016, Revised: 13-04-2016, Accepted: 20-04-2016

\begin{tabular}{|l|c|}
\hline \multicolumn{2}{|c|}{ Access this article online } \\
\hline Website: & Quick Response code \\
www.jimrp.com & \\
\hline DOI: & \\
10.21276/ijmrp.2016.2.3.023 & \\
\hline
\end{tabular}

Since MRI or CT scan is a routine investigation for every epileptic patient, except patients with documented Petite mal, or Idiopathic generalized epilepsy variants, we tried in this study to estimate the presence of $\mathrm{SCl}$ discovered incidentally in elderly patients having single or multiple unprovoked seizures or epilepsy,

It is very well known that epilepsy is a cortical phenomenon and silent strokes are mostly is a subcortical disease, but the presence of these silent strokes can be an indirect sign of more wide spread atherosclerotic changes causing very small cortical infarcts that cannot be visualized by regular CT scan or MRI sometimes, and these cortical SCl can be the focus of epileptic discharges.

Stroke is the commonest cause of seizures and epilepsy in the elderly population, it occur in about $10 \%$ of stroke patients. $5 \%$ are early-onset seizures (within the first days after the stroke) and another $5 \%$ are late-onset seizures (within 6 to 12 months after the stroke). ${ }^{11}$ In addition to that the onset of seizures in late life is associated with a striking increase in the risk of stroke. ${ }^{12} \mathrm{C}$.Y Sung and N. S. Chu reported that 23 out of 118 patients had Silent infarcts in their CT scans as they were investigating the relation between thrombotic stroke and epilepsy in elderly population. ${ }^{13}$ 


\section{PATIENTS AND METHODS}

This cross-sectional study (survey) was carried out in Rizgary Teaching Hospital, Erbil, Iraq from January to May, 2010. Patients were included in this study if they are middle aged and elderly patients (age range 50 and above) having unprovoked acquired first seizure or multiple seizures, previously or recently diagnosed as epileptic regardless the number of fits which could be single or multiple, having history of recent or old stroke or TIA and now presented with seizure. Patients with different CNS pathology were included (like brain tumors) to estimate the percentage of Silent stroke in between all patients. Patient with multiple sclerosis or leukodystrophy, seizures since early childhood or family history of hereditary epileptic syndrome and metabolic cause of seizures were excluded from the study. 100 patients were included in this study. Verbal informed consent was taken from the patients after explaining the design and aims of the study, and all had no objection to participating in the study. The Research Committee at the College of Medicine/ Hawler Medical University approved the study protocol. A questionnaire form was used to collect information from the patients regarding general health and history of medical diseases, such as, hypertension, diabetes mellitus
(DM), coronary heart disease, smoking and other vascular risk factors. Subjects were examined for physical and neurological signs or features of possible silent strokes, such as, exaggerated reflexes, pyramidal weakness, mild cerebellar signs, sensory signs, or long tracts signs. The MRI images were examined and interpreted through collaborative discussions between a consultant Radiologist and a consultant Neurologist (T1, T2 and FLAIR sequences were obtained). The MRI scanner was Siemens 1.5 tesla (Siemens, Erlangen, Germany). Silent infarcts were considered if they were smaller than $15 \mathrm{~mm}$ in diameter involving the subcortical white matter, and periventricular structures such as basal ganglia, thalamus, and internal capsule. Participants were investigated for dyslipidemia (serum cholesterol more than 200 $\mathrm{mg} / \mathrm{dl}$, and serum triglyceride more than $150 \mathrm{mg} / \mathrm{dl}$ ) and almost all patients had abnormal EEG studies.

The Statistical Package for Social Sciences version 15 (SPSS Inc., Chicago, IL, USA) was used for data analysis. Chi square test was used for association between $\mathrm{SCls}$ and risk factors. Student t-test was used to compare the means of 2 numerical variables. A $p$-value of $\leq 0.05$ was considered statistically significant.

Table 1: Distribution of sample by gender.

\begin{tabular}{|c|c|c|c|c|c|c|c|}
\hline \multirow[t]{2}{*}{ Age (years) } & \multicolumn{2}{|c|}{ Male } & \multicolumn{2}{|c|}{ Female } & \multicolumn{2}{|c|}{ Total } & \multirow[t]{2}{*}{$P$} \\
\hline & No. & $\%$ & No. & $\%$ & No. & $\%$ & \\
\hline $50-59$ & 12 & 19.67 & 8 & 20.51 & 20 & 20 & 0.8 \\
\hline $60-69$ & 16 & 26.23 & 12 & 30.77 & 28 & 28 & \\
\hline $70-79$ & 30 & 49.18 & 16 & 41.03 & 46 & 46 & \\
\hline 80 and above & 3 & 4.92 & 3 & 7.69 & 6 & 6 & \\
\hline Total & 61 & 100.00 & 39 & 100.00 & 100 & 100 & \\
\hline
\end{tabular}

Table 2: Prevalence of silent strokes by age.

\begin{tabular}{lccccc}
\hline Age (years) & N & Male & Female & Total & \% (for each age group) \\
\hline $\mathbf{5 0 - 5 9}$ & 20 & 6 & 1 & 7 & 35 \\
$\mathbf{6 0 - 6 9}$ & 28 & 9 & 4 & 13 & 46 \\
$\mathbf{7 0 - 7 9}$ & 46 & 22 & 7 & 29 & 63 \\
$\mathbf{8 0 +}$ & 6 & 2 & 2 & 4 & 67 \\
Total & 100 & 39 & 14 & 53 & 53 \\
\hline
\end{tabular}

DM: Diabetes Mellitus, CAD: coronary artery diseases, AVMs: arteriovenous malformations

Table 3: Co-morbidities observed in epileptic patients

\begin{tabular}{lcccccc}
\hline Comorbidities & \multicolumn{2}{c}{ Male $\mathbf{n}=\mathbf{6 1}$} & \multicolumn{2}{c}{ Female $\mathbf{n}=\mathbf{3 9}$} & \multicolumn{2}{c}{ Total $\mathbf{n = 1 0 0}$} \\
\cline { 2 - 7 } & No. & $\%$ & No. & $\%$ & No. & $\%$ \\
Hypertension & 31 & 50.8 & 29 & 74.4 & 60 & 60 \\
DM & 10 & 16.4 & 10 & 25.6 & 20 & 20 \\
Hyperlipidemia & 16 & 26.2 & 15 & 38.5 & 31 & 31 \\
CAD & 8 & 13.1 & 8 & 20.5 & 16 & 16 \\
Smoking & 32 & 52.5 & 2 & 5.1 & 34 & 34 \\
Old stroke & 26 & 42.6 & 10 & 25.6 & 36 & 36 \\
Brain tumors or metastasis & 6 & 9.8 & 6 & 15.4 & 12 & 12 \\
AVMs & 4 & 6.6 & 0 & 0.0 & 4 & 4 \\
Alzheimer Disease & 11 & 18.0 & 1 & 2.6 & 12 & 12 \\
\hline
\end{tabular}

Table 4: Radiological manifestations observed in the studied sample.

\begin{tabular}{lcc}
\hline MRI results & No & $\%$ \\
\hline Silent strokes & 35 & $35 \%$ \\
Silent strokes and major stroke & 18 & $18 \%$ \\
Only major stroke & 16 & $16 \%$ \\
Brain tumors or metastasis & 12 & $12 \%$ \\
AVMs & 4 & $4 \%$ \\
No finding & 14 & $14 \%$ \\
\hline
\end{tabular}




\section{RESULTS}

Table 1 shows that more than half $(61 \%)$ of patients were males. No significant differences in the age distribution of both sexes was detected $(P=0.8)$. It is evident in the same table that $46 \%$ of patients were in the age group 70-79 years.

All patients included in this study were nearly from same ethnic background, they were all Iraqi Muslims and mostly Kurdish, living in Kurdistan region in the North of Iraq.

Table 2 shows that the highest prevalence of silent strokes was among patients aged 70 years and more. Around three quarters $(73.6 \%)$ of silent strokes patients were males (39 out of 53 patients).

Hypertension was the commonest comorbidity observed in the studied sample which is also the most common risk factor for having both silent strokes and major haemorrhagic and ischemic strokes. The second common risk associated with the presence of epilepsy in elderly population is history of old stroke (36\%), while smoking (34\%) and hyperlipidemia (31\%) are also common risks of association to silent stroke in the studied population.

The most common type of fit observed in the studied sample is partial or focal secondary generalized fits depending on family and witnesses descriptions and sometimes personal observation (73\%), Generalized Tonic-Clonic fits were described by very few patients. (Fig 1).

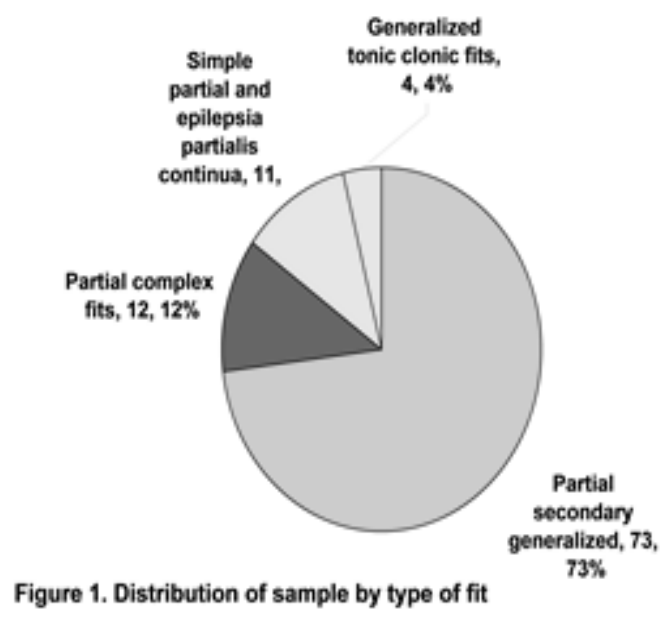

Silent strokes alone were observed in $35 \%$ of patients, while silent strokes in association with major stroke features were observed in another $18 \%$ of patients, another $16 \%$ of patients showed only major stroke; $28 \%$ of Patients had history or radiological features of anterior circulation stroke and $8 \%$ had posterior circulation stroke or combination. Some patients had no clear radiological cause for their epilepsy.

\section{DISCUSSION}

Most communities around the globe had substantial increase in the elderly population, including the Kurdish community in Iraq, partly because of the increase in medical awareness and the new medical managements of most medical and surgical conditions that increases mortality including Hypertension and coronary heart diseases, as a results new fields of Medical illnesses start to increase which may be related partially to aging process like Alzheimer disease and strokes including silent white matter ischemic strokes, Garrard J, et al. mentioned that The prevalence of AED use was $10.5 \%$ across all elderly nursing home residents. ${ }^{14}$
In this study I suggested that the estimation of the presence of those silent strokes may be an indirect way to relate epilepsy in elderly to small hidden ischemic cortical events that may represent a focal abnormal epileptic discharge.

The elderly have higher frequency of seizures activities, which can lead to serious consequences. The elderly differ from the young in that they may have many medical conditions that predisposes to epilepsy syndromes, like having numerous concomitant drugs, having different metabolic characteristics, and the presence of concomitant neurodegenerative, cerebrovascular, or neoplastic disease.

As many as $20 \%$ to $30 \%$ of epileptic patients may be misdiagnosed as psychiatric disorders or cardiovascular diseases like arrhythmias. Many of elderly epileptic patients may have cardiovascular syncope, with abnormal movements due to cerebral hypoxia, which may be difficult to differentiate from epilepsy on clinical grounds. ${ }^{15-17}$

In our studied sample we found that epilepsy type was partial secondary generalized in $73 \%$ of patient and partial complex type in $12.12 \%$ both these types are the expected types of epilepsy in elderly population since, it is mostly related to some focal pathological process like stroke, $\mathrm{SCl}$, neoplasm, and $\mathrm{AVM}$ involving the cerebral cortex while generalized epilepsy (4.4\%) which is mostly hereditary in nature affects younger age patients, patients exposed to anoxic-ischemic encephalopathy or metabolic brain diseases and neurodegenerative diseases patients which is less common pathological process observed in our studied population, nearly the same have been described by Hiyoshi T, and Yagi $\mathrm{K}^{18}$ they described that partial epilepsy was the epilepsy type in $76.3 \%$ of their studied sample, in addition to that Twentynine of 33 patients with generalized epilepsy were idiopathic in their studied sample, whereas all patients with partial epilepsy were symptomatic.

Simple partial and Epilespia partialis continua was the presenting epilepsy type in $11 \%$ of our studied sample. According to Rumbach $L$ and his colleagues, post stroke seizures may present initially with status epilepticus or one of its variants. ${ }^{19}$

Hypertension was the commonest associated factor in my studied sample as a cause for both established major stroke and silent strokes this had been observed by many other authors. ${ }^{20-23}$ The other common risk factors associated with the epilepsy in elderly population is history of previous major stroke, smoking, hyperlipidemia and DM.

The prevalence of SCls increases in patients with symptomatic strokes ranging from $10-40 \% .{ }^{24-26} \mathrm{~A}$ prevalence of $13 \%$ was reported in a small population study 25 of normal subjects but in a study on a large number of elderly subjects (age more than 65 years) the prevalence reaching up to $33 \% .{ }^{26}$ Several studies have examined the incidence of $\mathrm{SCls}$ and its relation to risk factors for recurrent symptomatic strokes and cognitive disorders. ${ }^{27-29}$ The majority of these studies had also demonstrated that age and hypertension strongly and independently correlated with SCls. ${ }^{30}$ In this study $35 \%$ of patients with epilepsy showed radiological evidences of $\mathrm{SCl}$, in addition to $16 \%$ of patients showed features of old major stroke, and $18 \%$ showed a combination of major stroke and some silent strokes, that makes silent strokes an important risk factor predicting the cause of epilepsy in elderly patients and may be the most important factor that may lead to epilepsy in the elderly population, and treating or stopping the 
formation of new silent strokes is of prime importance for decreasing the incidence of epilepsy in elderly people by frequent checking and managing risk factors of stroke like hypertension, $\mathrm{DM}$, hyperlipidemia and other risk factors.

\section{REFERENCES}

1. Adams RD, Victor M: Major categories of neurologic disease: Cerbrovascular diseases in; Ropper AH, Robert HB(edit.), principle of neurology, 8th edition, Mc Graw Hill, New York 2005, p 660-740.

2. Warlow C, Sudlow C, Dennis M, Wardlaw J, Sandercock P. Stroke. The Lancet, Volume 362, Issue 9391, Pages 1211 - 1224, 11 October 2003

3. Smith WS, Claiborne JS, Easton JD. Neurologic disorders: Cerebrovascular Diseases: in;Kasper DL, Fauci AS, Longo DL, Braunwald E, Hauser SL, Jameson JL(edit.) Harrison's Principle's of Internal Medicine, 16th edition, McGraw-Hill, New York 2005; pp 2372-93.

4. Ralph L. Vascular disease: Pathogenesis Classification and Epidemiology of Cerebrovascular Disease: in; Rowland LP, Merritt HH (edit.). Merrit's Neurology, 11th Edition, Lippincott Williams \& Wilkins, Philadelphia 2005; p 275-291.

5. Allen CM, Lueck CJ, Dennis M. Neurological diseases: Cerebrovascular diseases: in; Nicholas B, Nicki C, Brian W, John H (edit.). Davidson's principles and practice of medicine 20th edition, Churchil Livingstone, Oxford 2006: p 1200-1211.

6. Shinkawa A, Ueda K, Kiyohara Y, Kato I, Sueishi K, Tsuneyoshi M,Fujishima M. Silent cerebral infarction in a community-based autopsy Series in Japan. The Hisayama Study. Stroke. 1995; 26:380385.

7. Coutts SB, Hill MD, Simon JE, Silent ischemia in minor stroke and TIA patients identified on MR imaging. Neurology 2005; 65:513-517. 8. Vermeer SE, van Dijk EJ, Koudstaal PJ, Oudkerk M, Hofman A, Clarke R, Breteler MMB. Homocysteine, silent brain infarcts, and white matter Lesions: the Rotterdam Scan Study. Ann Neurol. 2002; 51:285-289.

9. Brown M. M., Rudd A., McGovern R., Ballotta E., Toniato A., Baracchini C., et.al . Transient Ischemic Attack - Proposed New Definition. N Engl J Med 2003; 348:1607-1609, Apr 17, 2003.

10. Jorgensen HS, Nakayama H, Raaschou HO, Gam J, Olsen TS. Silent Infarction in acute stroke patients: prevalence, localization, risk factors, and clinical significance: the Copenhagen Stroke Study. Stroke. 1994; 2597-104.

11. Olsen TS, Post-Stroke Epilepsy, Current Atherosclerosis Reports 2001, 3:340-344

12. P.Cleary, S.Shorvon, R.Tallis, Late-onset seizures as a predictor of subsequent stroke; The Lancet, Volume 363, Issue 9416, Pages 1184-1186.

13. C. Y Sung, N. S. Chu, Epileptic seizures in thrombotic stroke, J Neurol (1990) 237:166-170.

14. Garrard J, Cloyd J, Gross C, et al. Factors Associated with Antiepileptic Drug use Among Elderly Nursing Home Residents. J Gerontol A Biol Sci Med Sci 2000 Jul;55(7):M384-392.

15. Rowan AJ. Management of Seizures in the Elderly. Pharmacotherapy 2000 Aug;20(8 Pt 2):178S-184S.

16. Stephen LJ, Brodie MJ. Epilepsy in Elderly People.Lancet 2000 Apr 22;355(9213):1441-1446.

17. Zaidi A, Clough $P$, Cooper $P$, et al. Misdiagnosis of Epilepsy: Many Seizure-like Attacks have a Cardiovascular Cause. J Am Coll Cardiol 2000 Jul;36(1):181-184
18. Hiyoshi T, Yagi K. Epilepsy in the Elderly. Most of the late onset epilepsies were SPE with a relatively good prognosis. Epilepsia 2000;41 Suppl 9:31-35

19. Rumbach L, Sablot D, Berger E, et al. Status Epilepticus in Stroke: Report on a Hospital-Based Stroke Cohort. Neurology 2000 Jan 25;54(2):350-354

20. Vermeer SE, Hollander M, Dijk EJ, Hofman A, Koudstaal PJ, Breteler MM. Silent brain infarcts and white matter lesions increase stroke risk in the general population: the Rotterdam scan study. Stroke 2003; 34:1126.

21. Sang-Chol L.; Sang-Joon P.; Hyun-Kyun K.; Hyeon-Cheol G.; Chin-Sang C.; Hong Sk.; et.al ; Prevalence and Risk Factors of Silent Cerebral Infarction in Apparently Normal Adults; Hypertension. 2000;36:73-77.

22. Eguchi K, Kario K, Shimada K, ; Greater Impact of Coexistence of Hypertension and Diabetes on Silent Cerebral Infarcts, Stroke. 2003;34:2471-2474.

23. Al-Shimmery E, Amein S, Al-Tawil N, Prevalence of silent stroke in Kurdistan, Iraq. Neurosciences 2010; Vol. 15 (3): 7-11.

24. Price TR, Manolio TA, Kronmal RA, Kittner SJ, Yue NC, Robbins J,Anton-Culver H, O'Leary $\mathrm{DH}$. Silent brain infarction on magnetic resonance Imaging and neurological abnormalities in communitydwelling older adults. The Cardiovascular Health Study CHS Collaborative Research Group. Stroke. 1997; 28:1158-1164

25. Lee SC, Park SJ, Ki HK, Gwon HC, Chung CS, Byun HS, Shin KJ, Shin MH, Lee WR. Prevalence and risk factors of silent cerebral infarction in apparently normal adults. Hypertension. 2000; 36:73-77 26. Howard G, Wagenknecht LE, Cai J, Cooper L, Kraut MA, Toole JF.Cigarette smoking and other risk factors for silent cerebral infarction in the general population. Stroke. 1998; 29:913-917.

27. Vermeer SE, Prins ND, Heijer TD, Hofman A, Koudstaal PJ, Breteler MM.Silent brain infarcts and the risk of dementia and cognitive decline. N Engl J Med 2003; 348:1215.

28. Dhamoon MS, Moon YP, Paik MC, Boden-Albala B, Rundek T, Sacco RL, et al. Functional and cognitive consequences of silent stroke discovered using brain magnetic resonance imaging in an elderly population. J Am Geriatr Soc 2004; 52:1045.

29. Vermeer SE, Hollander M, Dijk EJ, Hofman A, Koudstaal PJ, Breteler MM. Silent brain infarcts and white matter lesions increase stroke risk in the general population: the Rotterdam scan study. Stroke 2003; 34:1126.

30. Giele, JL, Witkamp, TD, Mali, WP, Graaf YV. Silent brain infarcts in patients with manifest vascular disease. Stroke 2004; 35:742-764.

\section{Source of Support: Nil. Conflict of Interest: None Declared.}

Copyright: (c) the author(s) and publisher. IJMRP is an official publication of Ibn Sina Academy of Medieval Medicine \& Sciences, registered in 2001 under Indian Trusts Act, 1882.

This is an open access article distributed under the terms of the Creative Commons Attribution Non-commercial License, which permits unrestricted non-commercial use, distribution, and reproduction in any medium, provided the original work is properly cited.

Cite this article as: Mohammed Tahir, Mutaz F Hummadi, Jaafer M. Kurmanji, Ihsan K. Al-Shimmery. Silent Strokes is a Risk for Epilepsy in Elderly Population. Int J Med Res Prof. 2016; 2(3):99-102. 